Journal of Social Sciences 7 (1): 63-75, 2011

ISSN 1549-3652

(C) 2010 Science Publications

\title{
Monitoring Educational Organizations' Culture of Sustainable Consumption: Initiating and Evaluating Cultural Change in Schools and Universities
}

\author{
Daniel Fischer \\ Institute for Environmental and Sustainability Communication (INFU), \\ Faculty of Sustainability Sciences, Leuphana University Lüneburg, Germany
}

\begin{abstract}
Problem Statement: Patterns of consumption are considered as a main driver of unsustainable development. In the debate, education and educational organizations are unisonous considered as a key player to contribute to a more sustainable socialization of young consumers. Both schools and universities are challenged to become places and life-worlds in which sustainable consumption can be learned and experienced. The objective of this paper was to explore how educational organizations can effectively engage their members in bringing about the aspired transformations and monitoring their effects. Approach: The study used a conceptual approach that included three steps. Firstly, the concept of an educational organization's Culture Of Consumption (COC) was adopted as an analytical frame of reference. In a second step, methodological propositions for changing the organizational COC were discussed drawing on the concepts of mode- 2 knowledge production and participatory change management. In a third step, existing tools and approaches to sustainability auditing in the educational context were screened and critically discussed against the background of recent innovations in mode- 2 approaches to sustainability evaluation. Results: The findings revealed that while existing sets of indicators did adequately account for key consumption-related organizational operations and to some extent for educational goals and aspirations, they failed to tap the realm of underlying and tacit basic assumptions that substantiate the essence of an organizational COC. To remedy this shortcoming, additional indicators and modifications were proposed. As a synthesis, a synoptic framework of a monitoring system for an educational organization's COC was presented. Conclusion: The study's results highlighted the need to develop monitoring frameworks that go beyond assessing operative performances and pay greater attention to reflective, interpretative and deliberative capacities in educational organizations.
\end{abstract}

Key words: Organizational culture, educational organizations, basic assumptions, sustainable consumption, self-evaluation, education for sustainable development, change management, monitoring system, cultural change, participatory approach, stakeholders, quality criteria, espoused norm0073

\section{INTRODUCTION}

Sustainable consumption as a cultural challenge: Many of the phenomena of global change that can be observed today are closely linked to the globalization of cultural patterns of consumption and production. The escalating ideal of a material-intensive lifestyle as it is characteristic for the industrialized world marks a central challenge to the concerns of sustainable development. Consequently, in chapter 4, Agenda 21 acknowledges the need to change unsustainable patterns of consumption and production. For this to happen, action is called for to develop a better understanding of the role of consumption and how to bring about more sustainable consumption patterns (UNCED, 1993). In chapter 36, education and educational organizations are unanimously ascribed to play a pivotal role in bringing about a change towards sustainable consumption. As UNESCO states, the aspired transition needs to be a cultural change: "To the extent that the global crisis facing humanity is a reflection of our collective values, behavior and lifestyles, it is, above all, a cultural crisis" (UNCED, 1993). What is asked of education is nothing less than "to promote attitudes and behavior conductive to a culture of sustainability" (UNCED, 1993).

The Worldwatch Institute's 2010 report on the state of the world acknowledges that so far educational organizations do not just "represent a huge missed opportunity to combat consumerism", but even more so play an active and "powerful role in cultivating consumerism" (Assadourian, 2010). Hence, educational organizations are challenged to critically reflect and 
transform their role as a socialization agency as to nurture and cultivate more sustainable patterns of consumption among their students. In light of this, the objective of this paper is to explore how educational organizations can effectively engage their members in the endeavor of bringing about the aspired transformations and monitoring their effects.

\section{MATERIALS AND METHODS}

Approach: The study employs a conceptual approach that involves three corresponding steps. Firstly, the concept of an educational organization's culture of consumption (COC) is explored as an analytical frame of reference. In a second step, methodological propositions for changing the organizational COC are discussed drawing on the concepts of mode-2 knowledge production and participatory change management. In a third step, existing tools and approaches to sustainability auditing in the educational context are screened and critically discussed against the background of recent innovations in the conceptualization of mode-2 approaches to sustainability evaluation.

Educational organizations as "cultures of consumption": Although an elusive number of definitions and theoretical approaches exist, culture in an organizational context can be said to be commonly understood and described as "a pervasive, eclectic, layered and socially constructed phenomenon, which is generated through values, beliefs and assumptions but expressed through artifacts, structures and behaviors" (Harris et al., 2002). This study adopts an analytical framework that conceptualizes different levels, themes and domains of cultural transmission relating to the domain of consumption and consequently affecting consumer learning. The theoretical outline of the framework is based on Schein's concept of organizational culture and research from the field of school and university culture. These strands are merged and applied to the domain of consumption, resulting in a framework that identifies contested domains on different levels in educational organization's Culture Of Consumption (COC) (Fig. 1).

Educational organizations are understood to bring about a distinct cultural order resulting from innerorganizational battles and negotiations over the selection of structural variants. Following the analytical perspective suggested by Schein, this cultural order manifests itself in layers on three different levels that refer to the "degree to which the cultural phenomenon is visible to the observer" (Schein, 2004).
The surface level of artifacts represents cultural manifestations that can be understood as "visible, tangible and audible remains of behavior grounded in cultural norms, values and assumptions" (Hatch, 1997). Artifacts can be categorized as physical (e.g., cafeteria architecture), behavioral (e.g., lunch time rituals) or verbal (e.g., specific jargon use). The first level of artifacts is underpinned by the second level of values and norms that the organizational actors "use as a way of depicting the culture to themselves or others" (Schein, 2004). Values refer to "social principles, goals and standards held within a culture to have intrinsic worth" (Hatch, 1997), including norms that pose unwritten rules. The third level entails patterns of shared and taken-for-granted assumptions that Schein regards as "the essence of a group's culture" (Schein, 2004). They reflect "deeper assumptions about more abstract general issues around which humans need consensus" (Schein, 2004) and relate to such broad notions as the nature of human nature, of reality and truth, of time and place. Taken for granted and strongly anchored in the organizational members' cognitive structure, assumptions are generally not debated or reflected upon and regarded as difficult to change. In further developments on Schein's approach to organizational culture, the specific function of symbols as mediators between the different levels of artifacts, values, norms and basic assumptions has been further advanced (Hatch, 1997).

The examination of contested themes and realms of contents in the organizational COC draws on the detailed and extensive ethnographic study of educational organizations by Helsper et al. (2001). The authors identify dimensions in which the cultural configuration of educational organizations forms, emerges and manifests as a result of inner-organizational battles. Related to consumption, these dimensions were specified and further elaborated to domains of an educational organization's COC. Exemplary aspects of these domains are outlined in Table 1.

Change management for a "culture of sustainable consumption": This study proposes that in order to unfold their full potential as promoters of sustainable consumption, educational organizations need to engage in a holistic development of their COC. In view of the multiple and intertwined layers of educational organizations' COC, the development of a "Culture Of Sustainable Consumption" (COSC) requires wholeschool (Henderson et al., 2004) respectively whole-ofuniversity (McMillan et al., 2009) approaches. 


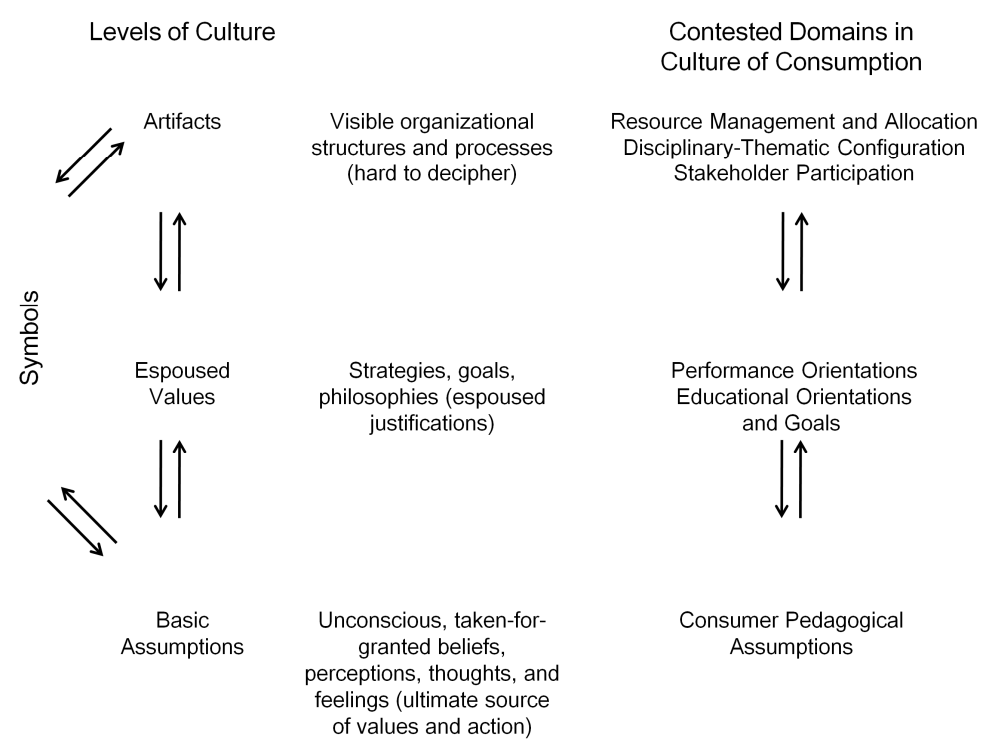

Fig. 1: Levels and domains of an educational organization's culture of consumption (after Schein, 2004)

Table 1: Domains of an educational organization's culture of consumption

\begin{tabular}{|c|c|}
\hline Domain & Exemplary Aspects \\
\hline Resource management and allocation & $\begin{array}{l}\text { In which ways does the organization allocate and manage its } \\
\text { spatial and temporal (e.g. cafeteria architecture, duration of lunch break), } \\
\text { financial (e.g., grants for consumption-related activities) } \\
\text { material (e.g., energy demand, emissions, waste) } \\
\text { human (e.g. staff training, knowledge management) } \\
\text { socio-ecological (e.g. networks, external partnerships) } \\
\text { administrative (e.g. job descriptions, responsibilities) resources? }\end{array}$ \\
\hline Disciplinary-thematic configuration & $\begin{array}{l}\text { Which (groups of) actors and subjects/courses address which themes of consumption? } \\
\text { Which research initiatives deal with which aspects of consumption? }\end{array}$ \\
\hline Stakeholder participation & $\begin{array}{l}\text { To what extent and with which degree of formality are internal and external stakeholders involved } \\
\text { in consumption-related decision-making? } \\
\text { How does consumption feature in formal and informal communication structures and flows? }\end{array}$ \\
\hline Performance orientations & $\begin{array}{l}\text { To what extent is the promotion of consumer learning understood and labeled an integral part of } \\
\text { the organizational mandate? } \\
\text { In how far do performances and achievements in the domain of consumption feature in the } \\
\text { examination and assessment procedures, grading schemes and are thus considered relevant with } \\
\text { respect to the awarding of degrees? }\end{array}$ \\
\hline Educational orientations and goals & $\begin{array}{l}\text { What consumption-related goals and objectives are pursued by organizational activities, how do } \\
\text { they relate to each other and how are they interpreted by different actors? } \\
\text { What didactical and methodological approaches are chosen in teaching and } \\
\text { learning about consumption-related issues? }\end{array}$ \\
\hline Consumer Pedagogical Assumptions & $\begin{array}{l}\text { What are dominant assumptions of youths and young consumers among adults, what are dominant } \\
\text { assumptions of adult consumers among youths and how do these assumptions relate to each other? } \\
\text { What are the organizational actors' evaluative assumptions regarding the function and role of their } \\
\text { organization as a consumer socialization agency? } \\
\text { What conceptions of a good life and of consumer identities are recognized and which are } \\
\text { dismissed by the dominant cultural order? }\end{array}$ \\
\hline
\end{tabular}

Propositions of sustainable change: The notion of sustainable development challenges conventional approaches to organizational cultural change in a number of respects. Gibbons and colleagues (Gibbons et al., 1994) have coined the term mode- 2 science as a label for a paradigmatic shift in research and knowledge production in the context of sustainable development.
Some central elements of mode-2 science that distinguish it from disciplinary mode- 1 forms are its greater focus on specific local application contexts and the inclusion of multiple perspectives in knowledge production, a broader participation of heterogeneous sets of practitioners and the transcending of disciplinary towards transdisciplinary frameworks (Gibbons, 2000). 
In this sense, the generation of transformative knowledge leading to practical outcomes becomes a proposition for a mode- 2 program in the context of sustainable development.

Educational organizations can be considered ideal settings for transdisciplinary mode- 2 approaches to the promotion of sustainable development. On the one hand they host different disciplinary traditions that are represented in distinct subject areas and academic socialization backgrounds of teaching staff as well as different faculties and research initiatives in institutions of higher education. On the other, educational organizations host different varieties of knowledge beyond disciplinary knowledge, for example with respect to practical operational routines and facility management, experiences with (un-)successful teaching and learning strategies on matters of consumption and students' consumption orientations and unwritten peer expectations. In the perspective of a mode-2 framework the "clash" of such different varieties of knowledge promises to be a fruitful and highly productive field for more refined approach for the "hidden systems of values and symbols" (Luks et al., 2007). Herein lay promising potentials for a participatory organizational engagement with the sustainable consumption agenda according to the principles of a mode- 2 intervention program.

A participatory approach to the initiation of cultural change for sustainability: Against the background of the foregoing considerations, this study opts for a participatory approach to the development of a COSC in educational organizations for both normative and functional reasons.

In a normative perspective, the concept of sustainable consumption itself requires a participatory approach, as organizations embarking on a journey towards a COSC are confronted with the difficulty that its destination cannot be pinpointed precisely. Although some basic requirements of the concept are generally agreed on (e.g., the earth's carrying capacity as an ecological limit), specifications of sustainable consumption remain contested and controversial (Fischer, 2010). In light of this, the concept of sustainable consumption provides merely "guard rails" (Worldwatch Institute, 2004) that open up a corridor in which the organizational stakeholders need to negotiate, define and reexamine goals, objectives and respective pathways towards an organizational COSC.

In a functional perspective, the symbolic nature of the organizational COC requires the organizational members' involvement in and ownership over the change process. As symbolic meaning attached to material artifacts is "neither embodied in the artifacts themselves nor entirely open to personal interpretation"
(Jackson, 2008), the de-construction and reconstruction of symbolic meaning in interpretative and reflexive processes feature as crucial elements in cultural change endeavors. Accrediting this symbolic dimension of consumption and the role of symbols in understanding the organizational COC (Hatch, 1997), cultural change depends on the contribution of a wide scope of perspectives from different organizational actors. Participatory and appreciative approaches bear the potential to effectively elucidate such authentic expressions of lived experiences from organizational members (Bergmark et al., 2009). Moreover, from a constructivist stance culture is perceived not as a manageable variable but as a shared perception mutually constructed in social interaction (Baumgartner, 2009). Hence, a "culture of sustainability" (UNESCO, 1998) cannot be prescribed in a top-down approach but takes broad social interaction and a discursive consciousness to evolve.

Monitoring, evaluation and indicators: The establishment of a change management infrastructure (e.g. the formation of change management team) and the development and implementation of change measures are essential steps in initiating cultural change processes. These need to be complemented by elements that allow for a closer observation of effects caused within the organizational COC. Monitoring systems serve such purposes. Broadly speaking, monitoring can be defined as "a system of activities with three critical components: it requires the regular collection of information, it requires an evaluation of that information and most importantly, it requires that the evaluation results in an institutional (project) action" (Kiesler et al., 1982; Richards, 1988). According to Richards (1988), three prototypical models of educational monitoring can be distinguished that differ according to their purpose:

- Compliance monitoring

- Diagnostic monitoring

- $\quad$ Performance monitoring

Compliance monitoring seeks to evaluate the organization's degree of compliance with fix and externally defined criteria (e.g., by laws, regulatory codes). The overall purpose is to ensure that the monitored system operates at some predetermined standard (Richards, 1988). Diagnostic monitoring usually follows a pre-post-design that assesses data for evaluative diagnosis (e.g., on student standards and curricula goals) and the design and implementation of treatment measures (e.g., teaching methods). Their 
effect is then again assessed in a post-test and followed up. Contrary to performance monitoring, diagnostic monitoring remains confined to the organization itself. The goal of performance monitoring is to provide a basis for benchmarking purposes based on aggregated school outcome measures, commonly by assessing students' achievements through testing (Richards, 1988). In that way, it seeks to enhance educational quality by stimulating competition between educational organizations. In a different terminology, diagnostic monitoring can be regarded as process monitoring and performance monitoring as outcome monitoring (Rossi et al., 2006). Apart from this, input or context monitoring marks a third type that focuses on given circumstances or existing input conditions framing processes and performances. While the presented typologies separate context, process and output or compliance, diagnostic and performance monitoring for analytical reasons, recent approaches stress the "indistinct delimitation" (Rode et al., 2008) of these analytical units and refer to educational context, process and output monitoring in an increasingly integrative way- not least in the context of the proliferating notion of total quality management and national educational reporting schemes.

Monitoring systems are based on indicators that can be understood as "proxy measures (i.e., not as direct ones) that point to certain states or conditions of a system and aim to simplify, measure and communicate complex trends and events" (Reid et al., 2006). They can relate to measurable (quantitative indicators) or observational/descriptive data (qualitative indicators). While quantitative indicators provide intersubjectively verifiable results and thus allow for advanced statistical operations and comparisons (Rode et al., 2008), the use of qualitative indicators is recommended in heterogeneous contexts where no set standards or objectives exist (Bormann et al., 2008). The development of a monitoring framework for activities in the context of the UN decade on "Education for Sustainable Development" (ESD) exemplifies how the integration of both quantitative and qualitative indicators ensures that a broad range of needs is addressed to enhance total quality improvement (Tilbury, 2009).

Plomp et al. (2009) point to the importance of considering stakeholders' differing purposes of and interests in operating monitoring systems. While monitoring initiatives might accrue from an educational organizations staff's intrinsic motivation to enhance the quality of their study (bottom-up), it might also be extrinsically forced upon by actors on the macro level seeking to engage in national benchmarking (top- down). Examining the locus of authority is a crucial step when considering monitoring initiatives as the differing foci might cause severe conflicts of interests. While macro level monitoring initiatives often focus on input and output, meso and micro level monitoring is rather directed at optimizing internal process (Plomp et al., 1992). As recent findings suggest, a widely shared perception among educational practitioners conceives self-evaluation as an endeavor imposed upon education organizations by the educational administration that serves to fulfill external control needs (Schildkamp et al., 2009; Vanhoof et al., 2009). It light of this, it must be distinguished between monitoring systems that are "intrinsically or extrinsically motivated" (Richards, 1988).

Requirements for a monitoring system for "cultures of consumption": What implications can be derived for the design and conceptualization of a monitoring system in the context participatory mode- 2 organizational development towards a COSC? In the context of an evaluation initiative on two Dutch system innovation processes on the sustainable development of agriculture, six guiding principles were developed as a response to the challenges in the context of mode-2 evaluation approaches (Regeer et al., 2009). These principles are applied below as guidelines to refine the contextualization and purpose of monitoring and evaluation in the context of cultural change towards a COSC in educational organizations:

- The focus of evaluative activities lays neither on performance measuring for benchmarking purposes nor on compliance monitoring based on predefined criteria, but on supporting the delivering change management team's continuous learning about effects of intervention strategies for a COSC

- Monitoring and evaluation are regarded as constitutive elements in a circular and sequential process of participatory organizational change management by being part of the iterative process of designing and implementing interventions and interpreting their effects

- The evaluation framework is developed in a participatory approach to adequately fit the information needs of the change management team by building on agreed forms of evidence

What requirements for the development of indicators can be derived? 
- The development of indicators for monitoring domains of COC seeks to engage stakeholders in deliberation and dialogue on relevant criteria in the local context. Indicators are dynamic and can be altered during the course of the intervention process to adapt to new circumstances and new priorities. They do not only seek to provide data, but to stimulate processes of meaning-making among the stakeholders. In this sense, "their function is not to assess but rather to perceive, or make visible, aspects that are or seem relevant" (Regeer et al., 2009) to a COSC

- In order to gain insight into factors contributing to the successful delivery of interventions and to provide indications about lessons learned within the intervention process, a specific type of indicator is required. It is suggested to elucidate perceived obstacles and main challenges on a regularly basis and to use this data to find strategies to address these issues and problems perceived as relevant in the further course of the intervention process

- Indicators need to bring to the fore different conditions that inhibit progression towards a COSC by focusing a broader set of stakeholder interests and their systemic and institutional constrains. As such constraints are elucidated, they can be adequately addressed and used to enhance the delivery and effect of interventions

As different monitoring approaches respond to different needs in the context of cultural change evaluation, the monitoring approach suggested in this study does not opt for one single favorable approach. Context monitoring has its strengths in making visible the conditions of cultural change action and can thus potentially provide valuable accounts of changing framing conditions. Performance monitoring targets important objectives for the organization's aspirations to become a model of a sustainable enterprise in its different administrative, operational, educational and research facets. Such measures also provide valuable feedback for the interpretation of intervention effects and the design of respective measures. Process monitoring is an indispensable element for a participatory approach to cultural change, as it focuses the actions taken and the implementation of change measures and contributes to optimizing the delivery of the intervention program. Likewise, a monitoring system in the context of cultural change towards a COSC has no preference for either quantitative or qualitative indicators, as both types of indicators serve different information needs.
Discursive forms feature prominently in the monitoring principles. As recent research on the evaluation of monitoring systems in the context of the European Social Fund suggests, the social contexts of monitoring activities deserve careful consideration. The authors stress that "the parties need to strike an implicit and/or explicit agreement on the quality of information to be shared" (Iannacci et al., 2009). Research on the interpretation and use of evidence in the educational context shows that the very questions of "what counts as evidence and for whom" (Cochran-Smith et al., 2009) need to be subject to processes of deliberation as well, or as Sollart (2005) asks in her elaboration on indicators for ESD: "What evidence would make us feel we are making progress?" A participatory development of measures of intervention and of an evaluative framework is also encouraged to ensure that the indicators developed are practicable and accepted by as many of the various different organizational actors as possible (Rode et al., 2008). This requires that contrary to approaches that apply predefined criteria, there must be room for measures of intrinsic value that do not serve as a means to the aspired end of a measurable outcome (Fitz-Gibbon, 1992).

Existing self-evaluation and auditing tools: The increasing interest in monitoring educational organizations' sustainability performance has led to the development of a number of schemes and monitoring systems in recent years. A total number of six approaches to sustainability self-evaluation, three each from the school education and higher education sector, have been considered and analyzed in terms of their suitability and applicability for a monitoring system for educational organizational COC.

School Education Context: In the UK, a selfevaluation tool for sustainable schools was developed based on findings reported by the Office for Standards in Education (Ofsted, 2003). The self-evaluation tool consists of two parts. The first part comprises six dimensions of school performance (school characteristics, stakeholders' views, achievements and standards, personal development and well-being, quality of provision and leadership and management) under which a total of 16 aspects are listed. The second part contains eight doorways (food and drink, energy and water, travel and traffic, purchasing and waste, buildings and grounds, inclusion and participation, local well-being and global dimension) that explore the school's contribution to overall sustainable development objectives. A team of school members rates the school's performance on each of the respective 
aspects on a progressive four-point-scale (Department for Education and Skills (UK), 2008).

On an international level, the School Development through Environmental Education (SEED) net study, organized by the Environment and Schools Initiative (ENSI), proposed a framework of quality criteria for ESD schools that comprise 15 areas presented in three main groups (quality of teaching and learning processes, school policy and organization and the school's external relations). The authors stress that the instrument does not intend to provide performance indicators or a tool for quality control, but seeks to give orientation and inspiration and to facilitate discussions within the school and with all of its stakeholders. Against this background, the quality criteria provided do not entail scoring grades or indicators (Breiting et al., 2005).

The SEED quality criteria informed the quality areas, principles and criteria as they have been formulated by the German sustainable schools program TRANSFER-21. Incorporating further auditing schemes from the educational (Bormann et al., 2005) and non-educational sector (e.g., EFQM, ISO), the program defines nine quality areas (learning culture, learning groups, competencies, school culture, opening of schools to the outside world, school management, school programme, resources and staff development), whereby each area is specified by principles and criteria and suggestions for possible learning arrangements and methods. The TRANSFER-21 approach goes beyond the SEED criteria insofar as it seeks to provide guidance for self-assessment and offers recommendations for possible forms of evidence (Transfer-21 'Quality and Competencies' Studying Group, 2007).

Higher education context: Initiatives to implement sustainability in the tertiary education sector have gained ground in recent years (Beringer, 2007). Within this context, auditing schemes have been developed and tested to monitor progress towards the implementation of sustainability principles into all facets of organizational life.

In 2005, the Higher Education Associations Sustainability Consortium (HEASC) issued a call for a campus sustainability rating system. In the following years, the North American Association For The Advancement Of Sustainability In Higher Education (AASHE) developed the voluntary self-reporting framework STARS (Sustainability Tracking, Assessment and Rating System) in a participatory and iterative process involving several stakeholders from the higher education sector. The version 1.0 of the STARS tool is structured in three categories (Education and Research, Operations as well as Planning, Administration and Engagement) that comprise 17 subcategories and a total number of 67 credit items to report on. STARS is based on a comprehensive reporting infrastructure that comprises different rating levels, publicly shared data and absolute scales that allow for benchmarking (AASHE, 2010).

The Assessment Instrument for Sustainability in Higher Education (AISHE) was initially developed by the foundation for sustainable higher education (DHO), a Dutch NGO, based on the principles of quality management as proposed by the European Foundation for Quality Management (EFQM) (Roorda, 2001). In its latest draft version 2.0, the scope of AISHE was broadened and its inventory restructured by an international expert group. Four roles were identified as central: Apart from delivering education and conducting research, institutions of higher education are operating organizations and act as members of society. Special emphasis is given to the idea of identity as a shared vision of the university, expressed for instance in the mission statement. The evaluation and reporting system of AISHE seeks to explore the matching of the identity module with the performances and processes in the four modules (operations, education, research and society), whereby each module consists of six criteria and each criterion is described by 5 development stages that are rated by the assessing team members. The instrument can be applied on several organizational levels, internally and externally (Roorda et al., 2009).

The Sustainability Assessment Questionnaire (SAQ) has been developed by the association of University Leaders for a Sustainable Future (ULSF), an association of university presidents and chancellors committed to implementing the principle of sustainability in higher education. The SAQ is regarded as "one of the most widespread instruments" (Beringer, 2007) used to ascertain organizations' performances in sustainability in higher education. The SAQ addresses seven main areas (curriculum, research and scholarship, operations, faculty and staff development and rewards, outreach and service, student opportunities as well as administration, mission and planning). It is designed as a tool serving both assessment and teaching purposes, while it is deliberately kept primarily qualitative and impressionistic and does not suggest any specific application procedure (University Leaders for a Sustainable Future, 2009).

\section{RESULTS}

Based on the premises of participatory change management and knowledge generation, a sequential 
model for participatory cultural change initiation is proposed that involves different groups of organizational members and stakeholders in the design of interventions and their implementation aimed at changing organizational structures and processes as well as underlying values and norms in contested domains of the organizational COC. According to the sequential steps of designing and implementing measures of intervention as well as monitoring and interpreting their effects, the initiation of a dynamic change processes towards a COSC can be conceptualized as an iterative process of action and reflection corresponding to the PDCA-cycle (Plan-DoCheck-Act), also known as Deming or Shewhart cycle (Fig. 2).

Importantly, the proposed approach rejects mechanistic concepts of change and builds on alternative conceptions of sustainability leadership and governance. Drawing on insights from complexity sciences, it is underpinned by an understanding of sustainability leadership as an attempt to "embrace the inevitability of continually changing dynamics in everyday life, while developing reasonable actions with others within an integrated framework that provides coherent direction, clear accountability and enough flexibility to allow for mid-course corrections" (Ferdig, 2007).

At the initial stage of a participatory cultural change endeavor, rigorous stakeholder analysis should be performed to ensure that all groups of actors are represented in a team in charge of the change process (change management team) (Scholes, 2004; Mehrizi et al., 2009). In educational organizations, such important groups of actors comprise students and teachers/lecturers, research and administrative staff, the management as well as specific external groups of stakeholders that play a powerful role as veto-actors in the inner-organizational decisionmaking in central domains of the organizational COC (e.g., school caterer, energy provider, parents, training companies).

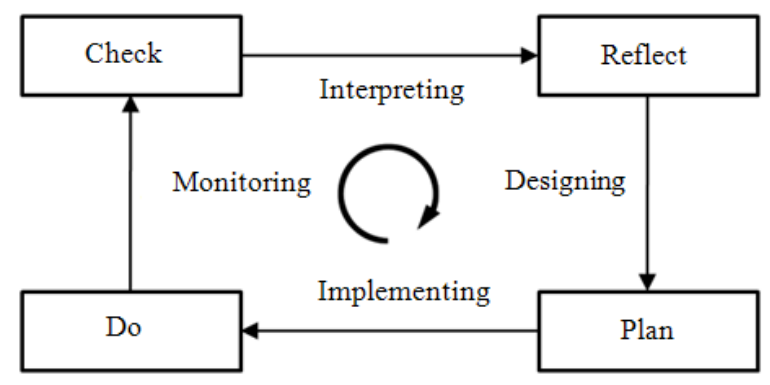

Fig. 2: Process steps in cultural change initiation
Drawing on experiences reported in the change management literature, changing (multiple) cultural artifacts promises to be a vital starting point for the initiation of cultural change in organizations (Higgins et al., 2006). Consequently, as an inductive approach, initial steps could be to design respective measures of intervention that seek to challenge the dominant cultural order in the organization by changing structures and processes in selected domains of the organizational COC that the change management team identifies as priority fields of action. Following the implementation of these measures, the effects of these measures and changes induced in the respective domains can then be monitored and checked to provide a basis for reflection and the design of modified or additional measures of intervention. Such cyclical progression based on the principles of action research (Huang, 2010) can be considered as "particularly suitable for dealing with the types of problems associated with sustainable development" (Regeer et al., 2009). Alternatively, in a rather deductive procedure, the cycle could be started with an assessment of baseline data in the different domains of the organizational COC. Either way, a central challenge to the outlined action-based approach lies in the operationalization of the framework of an organizational $\mathrm{COC}$ for evaluation and monitoring purposes.

\section{A synoptic framework for monitoring} organizational "cultures of consumption": The framework of COC comprises three levels of cultural manifestations that differ in their visibility and accessibility. The scope and complexity of aspects to consider pose a challenge to monitoring and assessment as it requires the development of instruments that measure structures, processes and values as well as intangible assumptions and orientations. Hence, it is proposed to merge the considerations on requirements for a monitoring system for mode- 2 interventions and the inventory of the outlined auditing and selfevaluation systems into a synoptic framework.

From the six evaluation systems analyzed, a total number of 352 indicators and quality criteria can be extracted. When these are assigned to the different domains and exemplary aspects of an educational organization's COC (Table 1), it becomes obvious that while a great number of potential indicators and quality criteria can be identified for the levels of artifacts and espoused norms and values, the included sustainability evaluation instruments fail to adequately account for the realm of basic assumptions that Schein refers to as cultural essence (Schein, 2004). Table 2 provides an overview of exemplary indicators and quality criteria from different instruments for the respective domains of COSC. 
Table 2: Exemplary indicators and quality criteria for a monitoring of an educational organization's COSC

\begin{tabular}{|c|c|c|}
\hline Cultural domain & Exemplary indicator/criterion (modified) & Original Source \\
\hline \multirow[t]{9}{*}{$\begin{array}{l}\text { Resource management } \\
\text { and allocation }\end{array}$} & $\begin{array}{l}\text { Allocation of appropriate time for the students' work with sustainable consumption, } \\
\text { as well as for the teachers' reflections and clarifications on education for sustainable } \\
\text { consumption issues at the organization }\end{array}$ & SEED (Breiting et al., 2005) \\
\hline & $\begin{array}{l}\text { Consideration of sustainable development in maintenance, refurbishment or new } \\
\text { build projects as well as in maintenance, improvement or design projects in the } \\
\text { organization's grounds. }\end{array}$ & $\begin{array}{l}\text { S3 (Department for Education } \\
\text { and Skills (UK), 2008) }\end{array}$ \\
\hline & $\begin{array}{l}\text { Percentage of procurement spending that can be regarded sustainable according to } \\
\text { (inter)nationally accepted standards }\end{array}$ & AISHE (Roorda et al., 2009) \\
\hline & $\begin{array}{l}\text { Percentage of employees that the institution ensures sustainable compensation so that } \\
\text { they earn enough to meet their basic needs (sustainable compensation) }\end{array}$ & STARS (AASHE, 2010) \\
\hline & $\begin{array}{l}\text { Audit of the organization's different focus areas (e.g., food and drink, energy and water, } \\
\text { travel and traffic, purchasing and waste) from a sustainability perspective }\end{array}$ & $\begin{array}{l}\text { S3 (Department for } \\
\text { Education and Skills (UK), 2008) }\end{array}$ \\
\hline & $\begin{array}{l}\text { Recognition of sustainable consumption contributions of faculty members in criteria } \\
\text { for hiring and promotion/tenure }\end{array}$ & $\begin{array}{l}\text { SAQ (University Leaders for a } \\
\text { Sustainable Future, 2009) }\end{array}$ \\
\hline & $\begin{array}{l}\text { Internal approach to staff development and training oriented towards the priorities } \\
\text { of the organization's program focused on the promotion sustainable consumption }\end{array}$ & $\begin{array}{l}\text { TRANSFER (Transfer-21 'Quality } \\
\text { and Competencies' Studying Group, 2007) }\end{array}$ \\
\hline & $\begin{array}{l}\text { Involvement in local, national and/or international networks with relevance for } \\
\text { education for sustainable consumption }\end{array}$ & TRANSFER (Transfer-21 'Quality \\
\hline & $\begin{array}{l}\text { Formal responsibilities reinforce the organization's commitment to sustainable } \\
\text { Consumption }\end{array}$ & $\begin{array}{l}\text { SAQ (University Leaders for a } \\
\text { Sustainable Future, 2009) }\end{array}$ \\
\hline Disciplinary-Th & Amount of faculty and student research on sustainable consumption & SAQ (University Leaders for a \\
\hline Configuration & $\begin{array}{l}\text { Identification of courses and program offerings focusing on and relating to } \\
\text { sustainable consumption }\end{array}$ & $\begin{array}{l}\text { Sustainable Future, 2009) } \\
\text { STARS (AASHE, 2010) }\end{array}$ \\
\hline \multirow[t]{3}{*}{ Stakeholder participation } & $\begin{array}{l}\text { Inclusion of views of different internal and external stakeholders (e.g., learners, parents, } \\
\text { carers, local community) in the organization's work on sustainable consumption }\end{array}$ & $\begin{array}{l}\text { S3 (Department for Education } \\
\text { and Skills (UK), 2008) }\end{array}$ \\
\hline & $\begin{array}{l}\text { Institutionalized participation structures and opportunities for pupils, teachers and } \\
\text { parents to have a say and get involved in all issues and themes that affect them }\end{array}$ & $\begin{array}{l}\text { TRANSFER (Transfer-21 'Quality and } \\
\text { Competencies' Studying Group, 2007) }\end{array}$ \\
\hline & $\begin{array}{l}\text { Use of communications, services, contracts and partnerships to promote sustainable } \\
\text { consumption issues in different focus areas among stakeholders }\end{array}$ & $\begin{array}{l}\text { S3 (Department for Education and } \\
\text { Skills (UK), 2008) }\end{array}$ \\
\hline \multirow[t]{2}{*}{ Performance orientations } & $\begin{array}{l}\text { Commitments to the promotion of (education for) sustainable consumption is put } \\
\text { down in formal written statements of different organizational units }\end{array}$ & $\begin{array}{l}\text { SAQ (University Leaders for a) } \\
\text { Sustainable Future, 2009) }\end{array}$ \\
\hline & $\begin{array}{l}\text { Number of students who graduated from a degree program that has adopted at least } \\
\text { one sustainable consumption learning outcome }\end{array}$ & STARS (AASHE, 2010) \\
\hline \multirow{2}{*}{$\begin{array}{l}\text { Educational orientations } \\
\text { and goals }\end{array}$} & Aspects of sustainable consumption contained in graduate profiles & AISHE (Roorda et al., 2009) \\
\hline & $\begin{array}{l}\text { Degree to what the curriculum contains methodologies for acquiring a variety of } \\
\text { skills, knowledge and attitudes regarding sustainable consumption }\end{array}$ & AISHE (Roorda et al., 2009) \\
\hline $\begin{array}{l}\text { Consumer Pedagogical } \\
\text { Assumptions }\end{array}$ & $\begin{array}{l}\text { Interpretation and Reflection of theories-in-use (e.g., Dynamic Learning Agenda } \\
\text { (Regeer et al., 2009), Learning history (Regeer } \text { et al., 2009), Critical Incidents } \\
\text { (Kiesler } \text { et al., 1982), Clinical Inquiry (Schein, 1993)) }\end{array}$ & \\
\hline
\end{tabular}

Indicators for the realms of artifacts and espoused norms and values need to be complemented by approaches to tap the underlying realm of basic assumptions. Due to their elusive and unconscious character, basic assumptions are hardly accessible to a one-time large-scale assessment based on observations or questionnaires, but require a time and cost consuming in-depth approach (Martin, 2002). Schein takes the stance that an assessment of underlying assumptions requires trained external researchers. As an approach, he developed and suggests clinical research (Schein, 1993). Yet, such external support is often not available or affordable to educational organizations. More recently, some practical toolkits have been developed for self-administered cultural diagnosis in the educational context seeking to provide instruments for an elucidation of basic assumptions (Peterson et al., 2009; Kruse et al., 2009). Albeit the fact that such practical instruments are unanimously useful for addressing and raising awareness of tacit assumptions in cultural change initiatives, their explanatory power remains limited.

Against this background it is suggested to complement the monitoring of artifacts and espoused norms and values with indicators monitoring perceived obstacles, drivers, barriers and challenges in the process of implementation. In his classical distinction, Argyris' distinguishes between espoused theories and theoriesin-use (Argyris, 1976). While the former term refers to cognitions and values that people believe their behavior is based on, the latter refers to the cognitions and values as they are implied by their manifestation in practices and behavior. Argyris' distinction resembles Schein's distinction between espoused values and underlying basic assumptions. Dooley (1995) argues that in situations of perceived threat tacit underlying assumptions guide organizational members' actions as theories-in-use. In light of this, special attention should be given to the implementation process and such situations in which dissonance and incongruity with espoused values and norms become visible and observable, for example with respect to espoused and practiced sustainability-related teaching principles and methods (Qablan et al., 2009). As resistance to or expressions of discomfort with change can be explained both situational and dispositional (Bareil et al., 2007), organizational members' responses to change initiated by intervention measures must be 
carefully interpreted in terms of their respective meaning for underlying assumptions that develop as a group "learns to cope with its problems of external adaptation and internal integration" (Schein, 2004). Hence, the reactivity of measures and monitoring data on the team of actors should be considered likewise as accounts of cultural learning (Fitz-Gibbon, 1992).

Regeer and colleagues (Regeer et al., 2009) propose dynamic learning agendas or learning histories as suitable approaches to construct, discuss and archive experiences with challenges in the course of the intervention process and its adaptation to and translation into the organizational real-life-context (Bisset et al., 2009). Additionally, other action research methods such as critical incident technique (Chell, 1999) might bring productive results for the identification of assumptions in situations of perceived threat and tension.

\section{DISCUSSION}

The study's results highlight the need to extend techno-centered reformist approaches to organizational change for sustainable development and to progress towards culturally sensitive transformative approaches in order to bring about a change in the organizational COC. This requires the development of monitoring frameworks that go beyond assessing educational organization's operative performances and focus on the reflective and social learning capacities of local actors (Wals, 2006). While educational practitioners can draw on an exhaustive catalogue of indicators from existing instruments, these might need to be modified or complemented in order to meet the local information requirements and to stimulate learning on cultural change. This can be attributed to the fact that most indicators seek to identify manifestations, whereas for the purpose of learning the non-existence of manifestations provides an equally rich source of information. For example, while it is doubtlessly useful to identify existing subjects and courses addressing sustainable consumption issues, it is equally useful to complement such indicator with another indicator that reports on major obstacles and reservations in subjects and courses that do not engage with the sustainable consumption agenda. From such accounts, interpretative conclusions could be drawn with respect to the configuration of basic assumptions (for example towards the school's or university's mission as a sustainable consumer socialization agency) and further tested. The approach suggested would allow for a consideration of genuinely cultural realms that are widely neglected in conventional approaches to auditing and monitoring educational organization's sustainability performance. Its design allows for the application of elements of existing self-evaluation and auditing tools, integrates them into the broader context of a mode- 2 cultural change intervention program and complements them with additional learning indicators for the realm of basic assumptions. In this way, the proposed approach to the monitoring of organizational COC employs both qualitative and quantitative indicators and blends elements from both diagnostic and dialogic traditions of organization development (Bushe et al., 2009). Yet, in order to successful adapt, implement and apply such inductive approach to monitoring, it is necessary to overcome the widely shared reservations to self-evaluation and to build respective evaluation and deliberation capacity among change management teams responsible for the design, implementation, controlling and monitoring of measures of intervention (Fleming et al., 2010).

A challenge for the further advancement of the framework concerns the development of feasible and applicable approaches, methods and techniques suitable to inform and guide the process of collectively interpreting monitoring data on underlying cultural assumptions. Further inspirations can be borrowed from existing methods in the field of qualitative organizational culture research (Davey et al., 2001).

Furthermore, closer attention needs to be drawn to the evaluation and monitoring of unintended effects of cultural change interventions (Harris et al., 2002). In order to better account for impacts and effects triggered by intervention measures in complex and dynamic conditions-as opposed to predetermined performance or goal attainment measures-synergistic approaches and an integration of multiple methods are needed (Weitzman et al., 2009). Valuable insights for the further elaboration on instruments in this field can be borrowed from the discussions and recent enhancements of evaluation models influenced by systems-thinking (Williams et al., 2007).

\section{CONCLUSION}

In view of the urgency and the complexity of the challenges in the context of a cultural change towards sustainable consumption, new responsibilities arise for educational organizations. Schools and universities are called upon to explore new approaches and paths to stimulate collaborative, self-reflective and transformative learning and to take the lead in becoming authentic models of progression towards sustainability. 
The proposed framework for a mode- 2 intervention and monitoring approach seeks to contribute to this notion. It challenges conventional approaches to monitoring to re-consider the realms of underlying tacit assumptions and the role of interpretation and reflection in transforming educational organizational COC. Based on considerations substantiating the vital necessity for the involvement of organizational members at all stages of the process, it suggests responding to the difficulties with conventionally assessing basic cultural assumptions by conceptualizing monitoring as a reflective tool contextualized in a circular and sequential process of collective action and reflection.

Further empirical research on the practical applications of a participatory approach to initiate and evaluate cultural change towards a COSC in educational organizations will help to elucidate pathways and possibilities for schools and universities to transform their role as a socialization agency and to actively engage in nurturing and cultivating more sustainable patterns of consumption among their students. This research takes place in the context of the three-years research and development project "BINK Educational Institutions and Sustainable Consumption" (2008 - 2011, www.consumerculture.eu), funded by the German Federal Ministry of Education and Research.

\section{REFERENCES}

AASHE, 2010. Sustainability Tracking, Assessment and Rating System (STARS). Version 1.0 Technical Manual, Lexington. http://www.aashe.org/files/documents/STARS/ST ARS_1.0_Technical_Manual.pdf

Argyris, C., 1976. Single-loop and double-loop models in research on decision making. Admin. Sci. Q., 21: 363-375. http://www.jstor.org/stable/2391848

Assadourian, E., 2010. The Rise and fall of Consumer Cultures. In: State of the World 2010Transforming Cultures: From Consumerism to Sustainability, Starke, L. and L. Mastny (Eds.). Worldwatch Institute, Washington, D.C., ISBN: 978-0-393-33726-6, pp: 3-20.

Bareil, C., Savoie, A. and S. Meunier, 2007. Patterns of discomfort with organizational change. J. Change Manage., 7: 13-24. DOI: $10.1080 / 14697010701232025$

Baumgartner, R.J., 2009. Organizational culture and leadership: Preconditions for the development of a sustainable corporation. Sustain. Dev., 17: 102-113. DOI: $10.1002 / \mathrm{sd} .405$
Bergmark, U. and C. Kostenius, 2009. Listen to me when I have something to say: Students participation in research for sustainable school improvement. Improv. Schools, 12: 249-260. DOI: $10.1177 / 1365480209342665$

Beringer, A., 2007. The Luneburg sustainable university project in international comparison: An assessment against North American peers. Int. J. Sustain. Higher Educ., 8: 446-461. DOI: 10.1108/14676370710823609

Bisset, S., M. Daniel and L. Potvin, 2009. Exploring the intervention-context interface: $A$ case from a school-based nutrition intervention. Am. J. Evaluat., 30: 554-571. DOI: $10.1177 / 1098214009349792$

Bormann, I. and G. Michelsen, 2008. Synchronisation oder desynchronisation von innovationsprozessen [Synchronisation or de-synchronisation of innovation processes]?. Umweltpsychologie, 12: 43-55.

http://www.umps.de/php/artikeldetails.php?id=308

Bormann, I. and H. Manthey, 2005. SINA-Schulische Indikatoren für Nachhaltigkeitsaudit School Indicators for Sustainability Auditing (SINA). Berlin, http://bildungoekologie.de/index.php?option=com_content $\&$ task =view $\&$ id=39\&Itemid=31

Breiting, S., M. Mayer and F. Mogensen, 2005. Quality criteria for ESD-schools. Austrian Federal Ministry of Education, Science and Culture, Vienna, ISBN: 3-85031-048-5

Bushe, G.R. and R.J. Marshak, 2009. Revisioning organization development: Diagnostic and dialogic premises and patterns of practice. J. Applied Behav. Sci., 45: 348-368. DOI: 10.1177/0021886309335070

Chell, E., 1999. Critical Incident Technique. In: Qualitative Methods in Organizational Research, a Practical Guide, Cassell, C. and G. Symon (Eds.). SAGE, London, ISBN: 0-8039-8770-6, pp: 51-72.

Cochran-Smith, M. and Boston College Evidence Team, 2009. "Re-Culturing" teacher education: inquiry, evidence and action. J. Teacher Educ., 60: 458-468. DOI: 10.1177/0022487109347206

Davey, M.K. and G. Symon, 2001. Recent Approaches to the Qualitative Analysis of Organizational Culture. In: The International Handbook of Organizational Culture and Climate, Cooper, C.L. (Ed.). Wiley, Chichester, ISBN: 978-0471491262, pp: 123-142.

Department for Education and Skills (UK), 2008. s3: Sustainable School Self-Evaluation. DCSF Publication, London, ISBN: 978-1-84775-181-2. 
Dooley, J., 1995. Cultural aspects of systemic change management. Proceedings of ASQC Conference, Oct. 20, pp: 13. http://www.well.com/user/dooley/culture.pdf

Ferdig, M.A., 2007. Sustainability leadership: Cocreating a sustainable future. J. Change Manage., 7: 25-35. DOI: 10.1080/14697010701233809

Fischer, D., 2010. Sustainable consumption-mapping the terrain. An exploratory review of contested themes and their representation in consumer education. Int. J. Environ., Cultural, Econ. Soc. Sustain., 6: 207-226.

Fitz-Gibbon, C.T., 1992. The design of indicator systems, the role of education in universities, and the role of inspectors/advisers: A discussion and a case study. Res. Papers Educ., 7: 271-300. DOI: 10.1080/0267152920070304

Fleming, M.L. and J. Easton, 2010. Building environmental educators evaluation capacity through distance education. challenges in evaluation of environmental education programs and policies. Evaluat. Program Plann., 33: 172-177. DOI: 10.1016/j.evalprogplan.2009.07.007

Gibbons, M., 2000. Mode 2 society and the emergence of context-sensitive science. Sci. Public Policy, 27: 59-163. DOI: 10.3152/147154300781782011

Gibbons, M., C. Limoges, and H. Nowotny, 1994. The new production of knowledge. SAGE, London, ISBN: 0-8039-7794-8, pp: 192.

Harris, L.C. and E. Ogbonna, 2002. The unintended consequences of culture interventions: A study of unexpected outcomes. British J. Manage., 13: 31-49. DOI: 10.1111/1467-8551.00221

Hatch, M.J., 1997. Organization Theory. Modern, Symbolic and Postmodern Perspectives, Oxford University Press, Oxford, ISBN: 978-0198774907, pp: 416.

Helsper, W., J. Böhme, R.T. Kramer and A. Lingkost, 2001. Schulkultur und Schulmythos: Rekonstruktionen zur Schulkultur I [School culture and School Mythos: Reconstructions Concerning School Culture]. Leske + Budrich, Opladen, ISBN: 978-3810027191, pp: 679.

Henderson, K. and D. Tilbury, 2004. Whole-School Approaches to Sustainability: An International Review of Sustainable School Programs. DEH and ARIES, Canberra, ISBN: 1-86408-979-2, pp: 65.

Higgins, J.M., C. Mcallaster, S.C. Certo and J.P. Gilbert, 2006. Using cultural artifacts to change and perpetuate strategy. J. Change Manage., 6: 397-415. DOI: 10.1080/14697010601087057
Huang, H.B., 2010. What is good action research? Why the resurgent interest? Action Res., 8: 93-109. DOI: $10.1177 / 1476750310362435$

Iannacci, F., T. Cornford, A. Cordella and F. Grillo, 2009. Evaluating monitoring systems in the European social fund context: A sociotechnical approach. Evaluat. Rev., 33: 419-445. DOI: 10.1177/0193841X09336262

Jackson, T., 2008. Sustainable Consumption and Lifestyle Change. In: The Cambridge Handbook of Psychology and Economic Behavior, Lewis, A. (Ed.). Cambridge University Press, Cambridge, ISBN: 978-0-521-85665-2, pp: 335-362.

Kiesler, S. and Sproull, L., 1982. Managerial response to changing environments: Perspectives on problem sensing from social cognition. Admin. Sci. Q., $\quad 27: \quad 548-570$. http://www.jstor.org/stable/2392530

Kruse, S.D. and K.S. Louis, 2009. Building Strong School Cultures. Corwin Press, Thousand Oaks. ISBN: 978-1412951821, pp: 200.

Luks, F. and B. Siebenhüner, 2007. Transdisciplinarity for social learning? The contribution of the German socio-ecological research initiative to sustainability governance. Ecol. Econ., 63: 418-426. DOI: 10.1016/j.ecolecon.2006.11.007

Martin, J., 2002. Organizational Culture. SAGE, London, ISBN: 978-0803972957, pp: 415.

Mcmillin, J. and R. Dyball, 2009. Developing a wholeof-university approach to educating for sustainability: Linking curriculum, research and sustainable campus operations. J. Educ. Sustain. Dev., 3: 55-64. DOI: 10.1177/097340820900300113

Mehrizi, M.H.R., Ghasemzadeh, F. and J. MolasGallart, 2009. Stakeholder mapping as an assessment framework for policy implementation. Evaluation, 15: 427-444. DOI: $10.1177 / 1356389009341731$

OFSTED, 2003. Taking the First Step ForwardTowards an Education for Sustainable Development. London, pp: 24. http://www.ofsted.gov.uk/content/download/10661 /127428/file/Taking\%20the\%20first\%20step\%20fo rward $\% 20$ towards $\% 20$ an $\% 20$ education $\% 20$ for $\% 20$ sustainable\%20development.pdf

Peterson, K.D. and T.E. Deal, 2009. The Shaping School Culture Fieldbook. Jossey-Bass, San Francisco. ISBN: 978-0787956806, pp: 160.

Plomp, T., H. Huijsman and E. Kluyfhout, 1992. Monitoring in educational development projects: The development of a monitoring system. Int. J. Educ. Dev., 12: 65-73. DOI: 10.1016/07380593(92)90021-D 
Qablan, A. and S. Al-Qaderi, 2009. How to change university faculty members attitudes and behavior in the context of education for sustainable development. Applied Environ. Educ. Commun., 8: 184-194. DOI: 10.1080/15330150903269407

Regeer, B.J., A.C. Hoes, M.V. Amstel-Van Saane, F.F. Caron-Flinterman and J.F.G. Bunders, 2009. Six guiding principles for evaluating mode-2 strategies for sustainable development. Am. J. Evaluat., 30: 515-537. DOI: 10.1177/1098214009344618

Reid, A., J. Nikel and W. Scott, 2006. Indicators for education for sustainable development: A report on perspectives, challenges and progress. Bath http://www.agf.org.uk/cms/upload/pdfs/CR/2006_ CR1515_e_education_for_sustainable_developmen t.pdf

Richards, C.E., 1988. A typology of educational monitoring systems. Educ. Evaluat. Policy Anal., 10: 106-116. DOI: 10.3102/01623737010002106

Rode, H. and G. Michelsen, 2008. Levels of indicator development for education for sustainable development. Environ. Educ. Res., 14: 19-33. DOI: 10.1080/13504620701843327

Roorda, N., 2001. AISHE-Auditing Instrument for Sustainability in Higher Education. Amsterdam. http://www.dho21.nl/documents/AISHEBook1.5.pdf, p. 119.

Roorda, N., C. Rammel, S. Waara and U. Fra Paleo, 2009. Assessment Instrument for Sustainability in Higher Education. Edition 2.0, $2^{\text {nd }}$ Draft, Tilburg, pp: 62. http://www.hu2.se/2010v/AISHE_2.0_Manual__2nd_draftswa.pdf

Rossi, P.H., M.W. Lipsey and H.E. Freeman, 2006. Evaluation. A Systematic Approach. SAGE, Thousand Oaks. ISBN: 978-0761908944, pp: 480.

Schein, E.H., 1993. Legitimating clinical research in the study of organizational culture. J. Counsel. Dev., 71: 703-708: http://search.ebscohost.com/login.aspx?direct=true $\& \mathrm{db}=$ pbh \&AN=9308177197\&site=ehost-live

Schein, E.H., 2004. Organizational Culture and Leadership. Jossey-Bass, San Francisco, ISBN: 978-0787975975, pp: 464.

Schildkamp, K. and A. Visscher, 2009. Factors influencing the utilization of a school selfevaluation instrument. Stud. Educ. Evaluat., 35: 150-159. DOI: 10.1016/j.stueduc.2009.12.001

Scholes, K., 2001. Stakeholder Mapping: A Practical Tool for Public Sector Managers. In: Exploring Public Sector Strategy, Johnson, G. and K. Scholes (Eds.). Financial Times Prentice Hall, Harlow, pp: 165-185. ISBN: 9780273711919, pp: 622.
Sollart, K., 2005. Framework on indicators for education for sustainable development. Some Conceptual Thoughts. Netherlands Environmental Assessment Agency. Den Haag, pp: 11. http://www.unece.org/env/esd/inf.meeting.docs/Fra mework\%20onESD\%20indic\%20NL.doc

Tilbury, D., 2009. Tracking our progress: a global monitoring and evaluation framework for the UN DESD. J. Educ. Sustain. Dev., 3: 189-193. DOI: 10.1177/097340820900300215

Transfer-21 'Quality and Competencies' Studying Group, 2007. Developing quality at 'ESD schools'quality areas, principles and criteria. Berlin, pp: 17. http://nachhaltigkeit-

lernen.org/coremedia/generator/unesco/en/04_The _20UN_20Decade_20in_20Germany/06__Publicat ions_20and_20documents/Transfer_2021_20-

_20Developing_20Quality_20at_20ESD_20School s.pdf

UNCED, 1993. Agenda 21. UN Department of Public Information, New York, pp: 351. http://www.un.org/esa/sustdev/documents/agenda2 1/english/Agenda21.pdf

UNESCO, 1998. Educating for a Sustainable Future. A Transdisciplinary Vision for Concerted Action, Paris, pp: 44. http://unesdoc.unesco.org/images/0011/001106/11 0686eo.pdf

University Leaders for a Sustainable Future, 2009. Sustainability Assessment Questionnaire for Colleges and Universities. Wayland, MA., pp: 12. http://www.ulsf.org/pdf/SAQforHigherEd09.pdf

Vanhoof, J., P. van Petegem and S. de Maeyer, 2009. Attitudes towards school self-evaluation. Stud. Educ. Evaluat., 35: 21-28. DOI: 10.1016/j.stueduc.2009.01.004

Wals, A.E.J., 2006. The end of ESD...the beginning of transformative learning. Emphasizing the ' $E$ ' in ESD. Proceedings of the Seminar on Education for Sustainable Development, Finnish UNESCO Commission, Helsinki, pp: 41-59. ISBN: 952-485255-1

Weitzman, B.C., T. Mijanovich, D. Silver and C. Brecher, 2009. Finding the impact in a messy intervention: Using an integrated design to evaluate a comprehensive citywide health initiative. Am. J. Evaluat., $\quad 30$ : 495-514. DOI: $10.1177 / 1098214009347555$

Williams, B. and I. Imam, 2007. Systems Concepts in Evaluation. An Expert Reader, Edge Press, Point Reyes. ISBN: 978-0-918528-22-3, pp: 226.

Worldwatch Institute, 2004. World in transition: Conservation and sustainable use of the biosphere. Earthscan, London, ISBN: 3-540-67106-4, pp: 478. 